\title{
Lessons from the USMA Faculty Development Workshop in teaching STEM courses during COVID-19
}

\author{
Eric D. Mowles, Chi K. Nguyen, Lam T. Nguyen, Jared E. Hollows, Melissa Eslinger, \\ Eileen M. Kowalski, F. John Burpo, Ryan Limbocker* \\ Department of Chemistry and Life Science, United States Military Academy, \\ West Point, NY 10996, USA \\ * Correspondence to R.L. (ryan.limbocker@westpoint.edu)
}

\begin{abstract}
Prior to the start of every academic year, the Department of Chemistry and Life Science in the United States Military Academy at West Point conducts a four-week Faculty Development Workshop (FDW). The purpose of FDW is to develop new faculty such that they are prepared to effectively educate students, and a critical hallmark of this program is in-depth feedback and mentorship from senior faculty. With nationwide uncertainty regarding the method of instruction for the upcoming semester, ranging from remote to in-person, and the possibility that schools may need to transition to exclusively remote learning during the semester due to health concerns from Coronavirus disease (COVID-19), this year's FDW incorporated different modes of instruction. Using classrooms with a maximum capacity of 20 students, new instructors conducted lessons fully remote, in-person with modified classroom paradigms, and through a hybrid approach where half of the students attended class synchronously online and the other half attended class in-person to facilitate social distancing requirements. In the process of preparing new instructors for the upcoming semester and equipping them with tools to teach under varied conditions, numerous lessons were learned on best practices for teaching this fall. In this manuscript, we describe our implementation of FDW and review the aforementioned teaching modalities, with a critical focus on the advantages and disadvantages of each teaching approach during COVID-19 and faculty perceptions on the difficulty and efficacy of each format of instruction.
\end{abstract}




\section{Introduction}

The United States Military Academy (USMA) at West Point is a 4-year undergraduate federal service academy with the mission to develop students academically, militarily, physically, and as leaders of character, which culminates with graduation at the rank $2^{\text {nd }}$ Lieutenant in the United States Army and an earned Bachelor of Science degree. This developmental model and critical mission require a faculty model that includes full-time military and civilian faculty with a blend of professional experiences and advanced degrees. ${ }^{1}$ The emphasis on development pertains to both students and faculty; in particular, the latter includes rotating military instructors who serve as faculty for a period of three years. Following three years of teaching, rotating military faculty return to other duties within the Army. This overturn necessitates the training of approximately one-fourth of our faculty each year. Approximately 18\% of our faculty are senior military officers with $\mathrm{PhD}$ degrees, 55\% are junior military with master's degrees, $27 \%$ are civilians with a blend of professional degrees, and $35 \%$ of faculty in total have doctoral degrees. ${ }^{1,2}$

Development is a major focus at USMA for all faculty, and the first developmental opportunity that Chemistry and Life Science (CLS) new faculty experience upon arrival to West Point is a summer Faculty Development Workshop (FDW). The CLS department operates like a small college comprising chemistry, chemical engineering, and life science disciplines. FDW orients new faculty to the USMA mission and the multi-faceted developmental model for students and faculty, and it also provides faculty with the resources necessary to lead instruction and constructively engage with students. During FDW, new instructors alternate between preparing and leading instruction to afford them the opportunity to collectively experience lesson material for the entire first-semester general chemistry course. When not leading class, instructors prepare for the lesson and participate as students.

The USMA student population represents a cross-section of the United States that are brought together in a regimented developmental environment for a 47-month experience. ${ }^{3}$ In this highly structured setting, class attendance is compulsory, and cadets are required to come to class prepared for the lesson by having read the assigned reading from their textbook and having completed the pre-class problems. ${ }^{4}$ Class time is then focused on critically analyzing the concepts 
covered in the reading and reinforcing their learning by solving problems, the latter of which students typically do individually or in pairs at chalkboards on the four walls of each classroom. This strategy places more responsibility on the learner, and working in groups or in-class interactions reinforce material and promote higher order thinking. ${ }^{5}$ Every interaction with our students, starting in the classroom, is considered a developmental opportunity ${ }^{1}$ towards the outcome of preparing them to serve as leaders of character with critical problem-solving skills. These interactions were somewhat limited last semester after Spring Break when the Academy underwent a rapid transition to remote learning in response to COVID- $19 .{ }^{6}$

In-person classes are well-aligned with the developmental model at West Point, which promotes student-centered active learning and direct mentorship. ${ }^{4,7,8}$ Over the last decade, much has been written to describe active learning. ${ }^{9}$ One definition of active learning is where students reflect on foundational ideas as they engage in problem-solving activities ${ }^{10}$ that depart from traditional lectures. ${ }^{11}$ Rather than passively receiving lectures, the migration from passive to self-directed learning requires students to engage critical thinking or processing skills to evaluate or solve problems $^{12-15}$ at the cognitive intersection of Bloom's taxonomy. ${ }^{16}$ This intersection of facts, coupled with actions to apply, analyze, or evaluate information as part of the learning process, represents an effective method by which students can critically comprehend the lesson objectives. ${ }^{17,18}$ Active learning, which includes data analysis and peer-led learning, shows measurable gains across student subpopulations with different backgrounds ${ }^{19-21}$ or preferred learning styles..$^{22}$ Most importantly, when faculty make pedagogical choices that foster a sense of belonging among students, it provides an inclusive learning environment. ${ }^{23}$ To maximize the effectiveness of learning strategies during class time, faculty need to be skilled at preparing instructional material that address specific learning objectives or facilitate activities that engage students to achieve these outcomes. Students report elevated interest in stimulating or activities based-classes compared to lectures, ${ }^{24}$ and real-time feedback, such as clicker questions, ${ }^{25}$ can provide faculty cues whereupon they clarify unclear concepts even among less-vocal students. ${ }^{26}$

The emphasis on student mentorship and active learning, defining characteristics at USMA, dictates a low student to faculty ratio that typically does not exceed 18:1. Also, first semester general chemistry is a required graduation requirement for all students at USMA. These facts result 
in high enrollment numbers in proportion to the student population of approximately 4,400 students and a requirement for instructor capacity to meet this demand. Therefore, most new faculty teach first-semester General Chemistry I. For this reason, General Chemistry I serves as the common course for use in FDW, which also supports faculty teaching later in second-semester General Chemistry II, Advanced General Chemistry I, and major-specific upper-level courses. Due to the small class sizes at USMA, the turnover of military faculty each year, and differing levels of faculty teaching experiences, there exists a critical need to ensure a high standard of instruction by all faculty. For instance, a typical fall semester of General Chemistry I includes circa 13 instructors and 35 sections, therein enrolling a total of approximately 650 students. To create an equitable and consistent course, a course director, who is in charge of the course and its many instructors, creates all lesson plans with specific learning objectives, assigns reading in the text and homework assignments, and creates quizzes, laboratory exercises, and tests. While each instructor is free to structure the lessons using a variety of teaching approaches, ${ }^{27-29}$ they must remain cognizant of the learning objectives that will be assessed through common graded events.

Through FDW, experienced faculty dedicate considerable time to mentor new instructors, attend practice classes, and provide constructive feedback for their professional development (see Supplementary Figure 1 for the common form used as a template for giving constructive feedback). In addition to this form, faculty give immediate feedback at the end of each new instructor's lesson that focuses on aspects of their teaching to sustain and improve going forward. The department head also attends each new instructor's final lesson for validation. Each new instructor teaches a minimum of four lessons, which they prepare for using the lesson materials that are provided by the course director (see Supplementary Figure 2 for an example lesson assignment sheet). These include specific learning objectives that correspond to a reading assignment, pre-class lesson preparation problems, and in-class/post-class homework problems.

The purpose of this manuscript is to share the lessons learned from FDW that we intend to leverage in upcoming academic terms. We first elaborate on the background of FDW, followed by the specific implementation methods used during FDW for either in-person, remote, or hybrid instruction, including a critical reflection on the advantages and disadvantages of each approach. Several of these lessons will also prove useful in future academic terms, even when fully in-person 
classes resume. While we focus on general chemistry in a collegiate course, we anticipate that these descriptions will prove broadly useful to the STEM education community. As an initial demonstration of the broader applicability of FDW, our department executes a common, shared general chemistry FDW session for new Life Science and Chemical Engineering faculty, where they diverge near the midpoint of FDW to focus on discipline specific lessons and practice teaching sessions within their program. Considering the current heterogeneity in the prevalence and spread of COVID-19 between states and nations, we anticipate that these considerations can be leveraged to prepare for, or rapidly adapt to, unique and potentially challenging fall and spring semesters.

\section{Results and discussion}

\section{Design and implementation of FDW}

The workshop begins with institution-specific training, an introduction to USMA resources, safety training, classroom management and conduct that is unique to USMA as a service academy, and at least three model lessons from experienced faculty with varied instructional styles. For the latter, deliberate efforts to create conditions for learning with useful and practical examples are effective ways to develop or sustain successful programs. ${ }^{30}$ In the absence of COVID-19, FDW would be administered entirely in-person with each instructor leading typically one or two lessons per week with coverage of the entire 4.0 credit hour course's 30 lessons of 75 minutes each and 8 laboratories of two hours each. Developing a "whole semester" perspective of the course in FDW is particularly advantageous towards framing the conceptual ties between lessons, therein facilitating new faculty members to present these threads to their students during the semester.

FDW has anecdotally proven successful in training new instructors, as assessed by their feedback. Indeed, new faculty are often qualitatively indistinguishable from experienced ones on the first day of classes. To render these observations more quantitative, we carried out a survey of the faculty that participated in FDW during the summer of 2020, to include new and experienced faculty. Prior undergraduate STEM teaching ranged from 0 to 25 years of experience for the 
anonymous survey participants, with an average of $5.6 \pm 2.0$ years of teaching (mean \pm standard error of the mean (s.e.m.), N=14, Figure 1a). We next asked faculty to self-assess their comfort with teaching before and after their first FDW, also considering that teacher experience and practice are clear potentiators of student learning. ${ }^{31}$ On a scale from one to five, faculty reported a pre-FDW score of $3.6 \pm 0.3$ and a post-FDW score of $4.6 \pm 0.1$ (mean \pm s.e.m., $N=14$, Figure $1 \mathbf{b}$ ). Pre- and Post-FDW data were compared using an unpaired, two-tailed student's t-test and found to be significantly different $(P=0.009)$. While this difference is significant, we highlight the relatively small sample size innate to one year of FDW participants. Systematic approaches in the future may quantify with greater confidence the efficacy of FDW, or similar programs, beyond this small dataset and qualitative observations from new and experienced faculty. Nonetheless, we are confident that FDW improves faculty confidence in their own teaching abilities and results in a better classroom experience for our dedicated cadets. Indeed, teaching experience has been positively correlated with student learning, where increases in teacher effectiveness from experience are greatest in a teachers' first years of instruction and are more pronounced in supportive and collegial workplaces. ${ }^{31}$

With the priority for the fall of 2020 being the health and safety of students, faculty, and staff and their families, FDW in the summer of 2020 necessitated consideration of different instructional delivery methods that may be implemented during the academic term. With department guidance, the modes of instruction considered and practiced during FDW were as follows: fully remote, fully in-person, and hybrid, which applied both remote and in-person instruction methods concurrently. This allowed new faculty to experience first-hand the advantages and disadvantages of each format of instruction and consider remedies to address the challenges associated with each modality. Moreover, this also provided an opportunity for experienced faculty to critically assess the advantages and disadvantages of each method. Currently, faculty have flexibility in determining the mode of instruction that best meets the needs of the discipline and course outcomes with full awareness that future safety constraints may necessitate at some point in the semester a transition to fully remote instruction. 


\section{Method 1: Remote teaching during COVID-19}

As the educational community comes to terms with maintaining social distancing and risk management in classrooms, ${ }^{32,33}$ numerous schools are migrating to virtual learning, where teachers may or may not have the teaching tools or training to use remote learning systems. Similarly, students can face shortages of reliable access to this technology or internet services, particularly from underprivileged communities or where resources must be shared among family members. ${ }^{34}$ In the spring of last semester, we made the transition from in-person to fully remote teaching during Spring Break. The decision was made to conduct synchronous remote instruction in our first-semester general chemistry course, and asynchronous remote instruction in second semester general chemistry course. A detailed summary of the execution, including explicit details on how we enacted our asynchronous remote teaching paradigm using recorded videos and Microsoft Teams $^{\circledR}$, and associated lessons learned from the past semester can be found in Nguyen et al. ${ }^{6}$ In brief, second semester general chemistry students appreciated the flexibility in completing the required coursework alongside their other synchronous classes, but instructors noted an inherent decrease in contact time with students and corresponding development opportunities. The decision for the current semester in both courses is to use synchronous class meetings.

In the general chemistry courses and FDW, instructors utilized Microsoft Teams ${ }^{\circledR}$ to meet virtually with students. Microsoft Teams ${ }^{\circledR}$, an institution supported platform, proved effective and useful for the remote instruction environment. In addition to Microsoft Teams ${ }^{\circledR}$, instructors employed a variety of teaching tools, such as $\mathrm{WACOM}^{\circledR}$ interactive writing instruments, iPads ${ }^{\circledR}$, portable whiteboards, a webcam and working on physical chalkboards in the classroom, or adapting slides from the coursetextbook. ${ }^{35}$ For demonstrating worked examples, the integrated Whiteboard application in Microsoft Teams ${ }^{\circledR}$ proved effective for collaborative problem solving between students. Using this technique, students in a class could work in small groups in separate channels within the Teams site with the instructor navigating between the channels to follow students' progress and provide feedback. Whiteboard.fi, ${ }^{36}$ a free teaching resource where students can solve problems on a digital whiteboards that is analogous to individual chalkboard work in the classroom, was also used to monitor student progress in real-time. Through this platform, an instructor can also share their digital whiteboard with the class, such as after setting up the basis 
of a problem, and provide live feedback to students. Similarly, instructors can have students share their screen and explain the process by which they solved a problem to highlight student work and promote collaboration.

The obvious advantage to remote teaching is that the health and safety risks of COVID-19 to faculty and students is maximally mitigated. However, the technology infrastructure and resources available need to be able to support remote instruction and learning. All students at USMA are issued new laptops with a touchscreen and have access to generally reliable Internet connectivity, which facilitates their access to the necessary digital learning platforms and resources. This certainly may not be the case nationwide, especially if students are geographically dispersed. However, technical issues nonetheless remained, as demonstrated during FDW, which necessitated time spent during class to solve administrative issues instead of focusing on the lesson content. Despite conscientious effort to call on cadets by name and to include all students in class discussions, it was markedly more challenging in a remote environment to ensure all students remained fully engaged in the lesson relative to in-person instruction. It was similarly more challenging to assess student understating, and developmental opportunities were reduced. Despite these challenges, strategies for keeping students engaged in remote coursework were similar to those used for in-person courses, to include varying the style and techniques employed, such as routinely switching between short instructor delivered lectures on specific concepts and experimentally demonstrating concepts, and having students work in groups, respond to classmates' questions, and solve problems though the use of varied platforms. ${ }^{37}$ A summary of advantages and disadvantages associated with remote teaching is provided in Figure 2, with recommendations for enhancing advantages and reducing the effects of the disadvantages.

\section{Method 2: In-person teaching during COVID-19}

Next, we briefly describe the conditions and perceived benefits of in-person instruction during COVID-19. At USMA, our teaching style undoubtedly lends itself best to students being physically present in the classroom. Class sizes are typically limited to 18 students with adequate chalkboards for students to work independently or in pairs to solve problems and receive 
immediate feedback from their instructors. Instructors are afforded flexibility in the style by which they engage with students and facilitate student-centered learning, such as the extent to which they have students work at chalkboards, work in small groups, or have instructor-facilitated discussions. In preparation for teaching in-person during COVID-19 and its health considerations, during FDW, we modeled safety procedures to assess their feasibility with students during the academic year. For instance, desks were spaced to allow for 6 feet of distance, face masks were worn, horizontal surfaces were sanitized after class, and hand sanitizer was readily available in each classroom.

Unique to COVID-19, compared to prior academic terms, was the need for distancing. For a classroom that accommodates 20 students with an enrollment capacity of 18 students, having students all in the same classroom would not meet distancing guidance. Larger classrooms could address this issue, but not the classrooms usually reserved for general chemistry. An in-person variation that was employed during FDW required one instructor to lead classroom instruction in two adjacent classrooms with approximately half the students in each room. This technique allowed for in-person engagement between students and instructors, and among students, but it required a level of experience and practice to manage two concurrent classrooms. This method worked well to maximize problem solving at the chalkboard by students with faculty feedback. Some faculty used minimal technology to focus on student engagement and chalkboard work, while others employed Microsoft Teams ${ }^{\circledR}$ to simultaneously engage students in both classrooms. This method afforded the advantage of having every cadet in class while abiding by strict social distancing guidelines; however, managing two classrooms effectively can be challenging and requires time to transition repeatedly between the two rooms. The advantages of this method are that assessment of student learning is more rapid, engagement can be sustained, and developmental opportunities are increased. Additionally, we also practiced and considered utilizing smaller class sizes with twice as many sections to facilitate social distancing. With sufficient resources, this would be an ideal way to ensure in-class learning and social distancing. We were not able to adopt this approach during the semester as it would not be pragmatic to double the number of sections from approximately 35 to 70 . Room allocation constraints, even in the absence of COVID-19, can make both these in-person methods impractical for many courses and institutions. 
We consider in-person classes to be the most efficient and effective form of teaching in the absence of health and safety restrictions. Ideally, in-person instruction would be conducted in one classroom. Nonetheless, each institution is well aware of the problems with teaching entirely inperson during the COVID-19 pandemic as we all prepare for the upcoming semester, considering that social distancing is challenging with the often-limited space available in a given classroom. Additionally, strict sanitation policies should be in place to control transmission from common touch points, and considerations of air flow and filtration within academic buildings should also be considered. To mitigate spread opportunities, instructors should consider transmission contact points and implement specific plans to reduce the associated risk. For example, we have asked our students bring and use their own chalk and erasers to class, and we use Microsoft Teams ${ }^{\circledR}$ for the distribution of all assignments and subsequent submission of all graded events so there is no passage of paper, all in order reduce shared contact points in our classroom. On the constructive end of in-person teaching, verbal and non-verbal feedback from students is immediate, rapport and developmental relationships are easier to form and foster, students are more likely to pay attention and remain engaged, and it facilitates more adaptive adjustments during class to address students' knowledge and interests. ${ }^{38-42}$ A summary of advantages and disadvantages associated with inperson teaching is provided in Figure 3, with recommendations for enhancing advantages and reducing the effects of the disadvantages.

\section{Method 3: Hybrid teaching during COVID-19}

The hybrid instruction method, which combines in-person and remote instruction, may provide the best compromise between the advantages of engaging students in-person and mitigating risks associated with COVID-19 within the infrastructure constraints of one classroom per section. In conducting hybrid instruction, an instructor occupied one classroom with half of the class attending in-person and the other half of the class attending remotely via Microsoft Teams ${ }^{\circledR}$. Students alternate attending in-person and remotely to achieve equity and sustain in-person contact time.

The practice with tools and lessons learned in the remote teaching subsection apply directly to the execution of class in this hybrid environment, with a reduction in the challenges associated with 
monitoring and attempting to engage students in a fully remote environment. Using a projector connected to the instructor's computer, students attending class remotely via Microsoft Teams ${ }^{\circledR}$ could be displayed on a projector screen and engage with the rest of the in-person class. Under the explicit direction to keep their cameras on, students attending class remotely were likely to be more engaged and attentive with the lesson material. Anecdotally, faculty experience and student feedback found that remote attendees will turn off their video feeds if given the option and often multitask on efforts not related to the lesson at hand. Moreover, being more visible to the instructor and other classmates can reinforce a sense of community and facilitate establishing of rapport.

Students attending remotely and in-person were able to solve problems individually or collaborate with each other using Whiteboard.fi or Whiteboard in Microsoft Teams ${ }^{\circledR}$, respectively. They could present their work to each other within their groups or to the whole class by sharing their computer screen on Microsoft Teams ${ }^{\circledR}$. In addition, students attending class in-person were also able to solve problems individually on the chalkboard and present their work to the class using their integrated laptop webcam. To maintain class cohesion, it was best to integrate students in-class with students attending remotely. This requires students attending class in-person to bring their laptops to effectively work with their remote classmates. With reliance on the technology for hybrid instruction, there is an inherent learning curve for students and faculty to adeptly navigate between different platforms, such as PowerPoint, the Whiteboard in Microsoft Teams ${ }^{\circledR}$, Whiteboard.fi, Microsoft Teams ${ }^{\circledR}$, or online videos and references that are incorporated into the lesson. Moreover, it can be challenging for faculty with all levels of teaching experience to engage two spatially disparate audiences and manage two different in-class groups that can have dynamic personalities per section. ${ }^{43,44}$

The clear disadvantage with the hybrid method is that only half of the students attend class inperson for a given lesson. Students would alternate between attending lessons in-person and remotely, which results in $50 \%$ of the classes attending in-person and vice versa. This method incurs greater risks from a health and safety perspective than the fully remote environment. Under the right conditions and with strict sanitization and social distancing regimens, hybrid classes can represent a reasonable compromise between promoting health and safety alongside the benefits of in-person instruction. We suggest that the decision to start remote, in-person, or hybrid should be 
made in consideration of the real-time situation of the pandemic at a particular college or university, in addition to state and federal guidance and physical space constraints for a given class. A summary of advantages and disadvantages associated with hybrid teaching is provided in Figure 4, with recommendations for enhancing advantages and reducing the effects of the disadvantages.

Moreover, we note that laboratories and demonstrations can be carried out in the hybrid environment more readily than in the fully remote environment. Demonstrations are relatively straightforward, as in the hybrid environment, an instructor need only align their webcam to face the experiment for the remote attendees. While easy to execute, these demos are undoubtedly less impactful for students in a virtual environment, as it is harder to physically experience the experiment and make observations on a two-dimensional screen in comparison to being physically present. Hybrid approaches can also be a useful compromise for laboratories. Using the laptop webcam, students can work in pairs to collaborate on laboratory experiments, where students alternate between physically completing the experiment in-person and serving as a virtual lab partner in taking detailed notes. Though this method, all students in a course can carry out all of the labs and gain hands on laboratory practice while meeting social distancing requirements. Additional safety measures will need to be implemented for COVID-19 purposes, such as students being more diligent in washing their hands prior to touching or adjusting their face masks to ensure no chemicals are transferred from their hands to their face or mask.

\section{Faculty perceptions on the teaching modalities}

Finally, we postulated that even within a controlled institution like West Point, faculty perceptions regarding the difficulty and effectiveness of these teaching modalities may be heterogeneous. To assess this prediction quantitatively within our FDW participants, we surveyed the same population described in Figure 1 (see Supplementary Figure 3 for the survey). Faculty were asked to indicate the method that they perceived as: 1) the most and least difficult to prepare for during COVID-19 (Figure 5a); 2) the most and least time consuming to prepare for during COVID-19 (Figure 5b), and 3) the best method for student learning during COVID-19 (Figure 5c). While heterogeneity clearly exists within our population, overt trends were established in our small 
dataset. Faculty considered hybrid teaching to be the most difficult to prepare for $(78.6 \%$ of responses), while in-person instruction was unanimously indicated as the least challenging in terms of preparation difficulty. Hybrid classes were reported as the most time consuming to prepare for (64.3\% of responses), while in-person was largely considered the least time consuming to prepare for (71.4\% of responses). Finally, in-person teaching was almost unanimously selected as the most effective for student learning (92.3\% of responses), while remote and hybrid teaching were nearly evenly split in terms of being the least effective for student learning at $53.8 \%$ and $46.2 \%$ of responses, respectively, in the collective opinion of surveyed faculty members.

The preference for in-person teaching and perceived elevated efficacy towards student learning could be a result, at least in part, of faculty familiarity with the method given that in-person instruction aligns with previous teaching experience. Indeed, we found in-person classes were reported as easier to prepare for and the least time consuming of the three methods (Figure 5). It should be noted that strict non-pharmaceutical interventions and safety regulations are in place at USMA, including but not limited to face mask use at all times, maintenance of social distancing, and sanitization of classrooms between each meeting. Compliance with these rules is strictly enforced and obeyed. These survey distributions with respect to faculty preferences are for a military academy and are very likely to be different at other universities where the incidence of COVID-19 is also different. In particular, USMA is in Orange County, New York, where the COVID-19 curve has remained largely flat for the entirety of July and August with approximately 8-15 new cases per day. ${ }^{45,46}$ Nonetheless, our dataset collectively agrees with the postulation that faculty preferences on the difficulty and efficacy of the remote, in-person, and hybrid teaching approaches are heterogeneous, adding further support to the notion that the decision of what teaching modality to adopt is based on complex and individual factors, such as specific teaching skills, preferences, and health statuses of the individual or people that they are in regular contact with, as well as university, local, and federal guidance related to COVID-19. 


\section{Conclusions}

Although FDW is a time intensive process where new instructors fully dedicate themselves to prepare to teach first-semester general chemistry in the upcoming term, it has proven invaluable to ensure a high standard of education that is consistent throughout the sections and among the many faculty teaching the course. This summer, as a result of COVID-19 and a need to adapt to health and safety guidance, FDW was leveraged to explore different methods of instruction alongside developing new instructors to effectively teach general chemistry. The methods of instruction explored included fully remote, in-person, and hybrid, which combined in-person and remote instruction. In doing so, advantages and disadvantages of each method were noted in developing the instructional plan for the fall academic term. Alongside these considerations, as well as considering the specific regional COVID-19 situation, state and federal guidance, course sizes, and available classrooms, we anticipate that the considerations and associated tools discussed herein will help educators worldwide as they prepare for upcoming semesters or adapt their courses and teaching methods rapidly according to the potentially dynamic global health situation. 


\section{Acknowledgements}

The authors thank the first semester general chemistry faculty from the summer of 2020 and all participants who contributed to FDW and the survey. We thank CLS colleagues for useful discussions over the years. We also sincerely thank our exceptional and inspiring students. All of our work is dedicated to providing them the best educational experience that we can, and we hope that these lessons and discussions will also help the STEM community.

\section{Author Contributions}

E.M. has served as the course director for first semester general chemistry from 2018-2020. C.K.N. was responsible for FDW from 2019-2020. F.J.B. provided department FDW planning and execution guidance, as well as instructor validation, from 2016-2020. L.N. and R.L. designed the survey and analyzed its results. R.L. wrote the first draft, and all authors critically contributed to the editing and revising of the manuscript.

\section{Competing interests}

The authors declare no competing interests related to this manuscript. The contents of this publication, including words, images, and opinions, are unofficial and not to be considered as the official views of the United States Military Academy, United States Army, or Department of Defense. Neither this publication nor its content, or products mentioned, are endorsed by the United States Military Academy, United States Army, or Department of Defense. 


\section{Data availability}

The data generated or analyzed in this study are included in the article. Deidentified raw data are available from the authors upon reasonable request.

\section{References}

1. Dean of the Academic Board. Educating Army Leaders; United States Military Academy: West Point, NY; 1-41 (2020).

2. Center for Faculty Excellence, United States Military Academy. New Instructor Information. https://www.westpoint.edu/centers-and-research/center-for-teaching-excellence/newinstructor/west-point-faculty (accessed 2020-08-25).

3. Nomination Information, United States Military Academy. https://www.westpoint.edu/admissions/prospective-cadets/nomination-information (accessed 2020-08-25).

4. Shell, A. E. The Thayer Method of instruction at the United States Military Academy: a modest history and a modern personal account. Probl. Resour. Issues Math. Undergrad. Stud. 12, $27-$ 38 (2002).

5. Gross, J. \& Carlson, B. M. Implementing active learning approaches into an upper-division biology course. CourseSource 5, (2018).

6. Nguyen, C. K., DeNeve, D. R., Nguyen, L. T. \& Limbocker, R. Impact of COVID-19 on general chemistry education at the United States Military Academy. J. Chem. Educ. (2020) doi:10.1021/acs.jchemed.0c00771.

7. Bolander, S. F. Class size and levels of student motivation. J. Exp. Educ. 42, $12-17$ (1973).

8. McKeachie, W. J. Class size, large classes, and multiple sections. Academe 66, 24-27 (1980).

9. Choi, Y., Jakob, S. \& Anderson, W. J. Active learning: developing self-directed learners through strong intellectual engagement. CourseSource 4, (2017).

10. Collins, J. W., O'Brien, N. P. The Greenwood Dictionary of Education. Santa Barbara, Calif: Greenwood (2011).

11. Knight, J. K. \& Wood, W. B. Teaching more by lecturing less. Cell Biol. Educ. 4, 298-310 (2005).

12. DebBurman, S. K. Learning how scientists work: experiential research projects to promote cell biology learning and scientific process skills. Cell Biol. Educ. 1, 154-172 (2002).

13. Gehring, K. M. \& Eastman, D. A. Information fluency for undergraduate biology majors: applications of inquiry-based learning in a developmental biology course. CBE Life Sci. Educ. 7, 54-63 (2008).

14. Lents, N. H., Cifuentes, O. E. \& Carpi, A. Teaching the process of molecular phylogeny and systematics: a multi-part inquiry-based exercise. CBE Life Sci. Educ. 9, 513-523 (2010).

15. Odom, D. P. \& Grossel, M. J. Using the two-hybrid screen in the classroom laboratory. Cell Biol. Educ. 1, 43-62 (2002). 
16. Revised Bloom's Taxonomy, Center for Excellence in Learning and Teaching, Iowa State University. $\quad$ https://www.celt.iastate.edu/teaching/effective-teaching-practices/revisedblooms-taxonomy/ (accessed 2020-08-25).

17. Airasian, P. W. Classroom Assessment: Concepts and Applications. Fourth Edition. (McGraw-Hill, P, 2001).

18. LW, A. et al. A Taxonomy for Learning, Teaching, and Assessing: A Revision of Bloom's Taxonomy of Educational Objectives. (Pearson, 2001).

19. Haak, D. C., HilleRisLambers, J., Pitre, E. \& Freeman, S. Increased structure and active learning reduce the achievement gap in introductory biology. Science 332, 1213-1216 (2011).

20. Kim, H. S. We talk, therefore we think? A cultural analysis of the effect of talking on thinking. Journal of Personality and Social Psychology, 83, 4, 828-842.

21. Snyder, J. J., Sloane, J. D., Dunk, R. D. P. \& Wiles, J. R. Peer-led team learning helps minority students succeed. PLOS Biol. 14, e1002398 (2016).

22. Jones, S. E. Reflections on the lecture: outmoded medium or instrument of inspiration? $J$. Furth. High. Educ. 31, 397-406 (2007).

23. Dewsbury, B. \& Brame, C. J. Inclusive teaching. CBE-Life Sci. Educ. 18, 2 (2019).

24. Ernst, H. \& Colthorpe, K. The efficacy of interactive lecturing for students with diverse science backgrounds. Adv. Physiol. Educ. 31, 41-44 (2007).

25. Knight, J. K., Wise, S. B. \& Southard, K. M. Understanding clicker discussions: student reasoning and the impact of instructional cues. CBE-Life Sci. Educ. 12, 645-654 (2013).

26. Welsh, A. J. Exploring undergraduates' perceptions of the use of active learning techniques in science lectures. J. Coll. Sci. Teach. 42, 80-87 (2012).

27. Wieman, C. \& Gilbert, S. The teaching practices inventory: A new tool for characterizing college and university teaching in mathematics and science. CBE-Life Sci. Educ. 13, 552569 (2014).

28. Freeman, S. et al. Active learning increases student performance in science, engineering, and mathematics. Proc. Natl. Acad. Sci. 111, 8410-8415 (2014).

29. Lund, T. J. et al. The best of both worlds: building on the COPUS and RTOP observation protocols to easily and reliably measure various levels of reformed instructional practice. CBE_Life Sci. Educ. 14, ar18 (2015).

30. Haras, C. Faculty development as an authentic professional practice. Higher Education Today https://www.higheredtoday.org/2018/01/17/faculty-development-authentic-professionalpractice/ (accessed 2020-08-25).

31. Kini, T. \& Podolsky, A. Does teaching experience increase teacher effectiveness? Palo Alto: CA Learning Policy Institute (2016).

32. Lieberman, M. Teaching in an empty classroom during COVID-19: benefits and drawbacks. Education Week https://www.edweek.org/ew/articles/2020/08/04/teaching-in-an-emptyclassroom-during-covid-19.html (accessed 2020-08-25).

33. Lieberman, M. COVID-19 \& remote learning: how to make it work. Education Week https:/www.edweek.org/ew/issues/reopening-schools/covid-19-remote-learning-how-tomake-it.html?cmp=SOC-SHR-FB (accessed 2020-08-25).

34. Kamenetz, A. Survey shows big remote learning gaps for low-income and special needs children. NPR.org https://www.npr.org/sections/coronavirus-liveupdates/2020/05/27/862705225/survey-shows-big-remote-learning-gaps-for-low-incomeand-special-needs-children (accessed 2020-08-25).

35. Tro, N. J. Chemistry: Structure and Properties. (Pearson Inc., 2018). 
36. Laxell, S. Whiteboard.fi. https://whiteboard.fi/ (accessed 2020-08-25).

37. Gaytan, J. \& McEwen, B. C. Effective online instructional and assessment strategies. Am. J. Distance Educ. 21, 117-132 (2007).

38. Bain, K. What the Best College Teachers Do, 1st ed. Harvard University Press: Cambridge, MA (2004).

39. Lowman, J. Mastering the Techniques of Teaching, 2nd Edition. Jossey-Bass: San Francisco, CA (1995).

40. National Research Council. How People Learn: Brain, Mind, Experience, and School; The National Academies Press: Washington, D.C., (2000). doi:10.17226/9853.

41. National Academies of Sciences, Engineering, and Medicine. How People Learn II: Learners, Contexts, and Culture; The National Academies Press: Washington, D.C., (2018). doi: $10.17226 / 24783$.

42. National Research Council. Reaching students: what research says about effective instruction in undergraduate science and engineering; The National Academies Press: Washington, DC, (2015). doi:10.17226/18687.

43. McCabe, M. F. \& González-Flores, P. Essentials of Online Teaching: A Standards-Based Guide, $1^{\text {st }}$ ed.; Routledge: New York (2017).

44. Ko, S. \& Rossen, S. Teaching Online: A Practical Guide, $4^{\text {th }}$ ed.; Routledge: New York (2017).

45. COVID-19 Map. Johns Hopkins Coronavirus Resource Center https://coronavirus.jhu.edu/map.html (accessed 2020-08-20).

46. The COVID Tracking Project. https://covidtracking.com/ (accessed 2020-08-20). 
Figures and legends
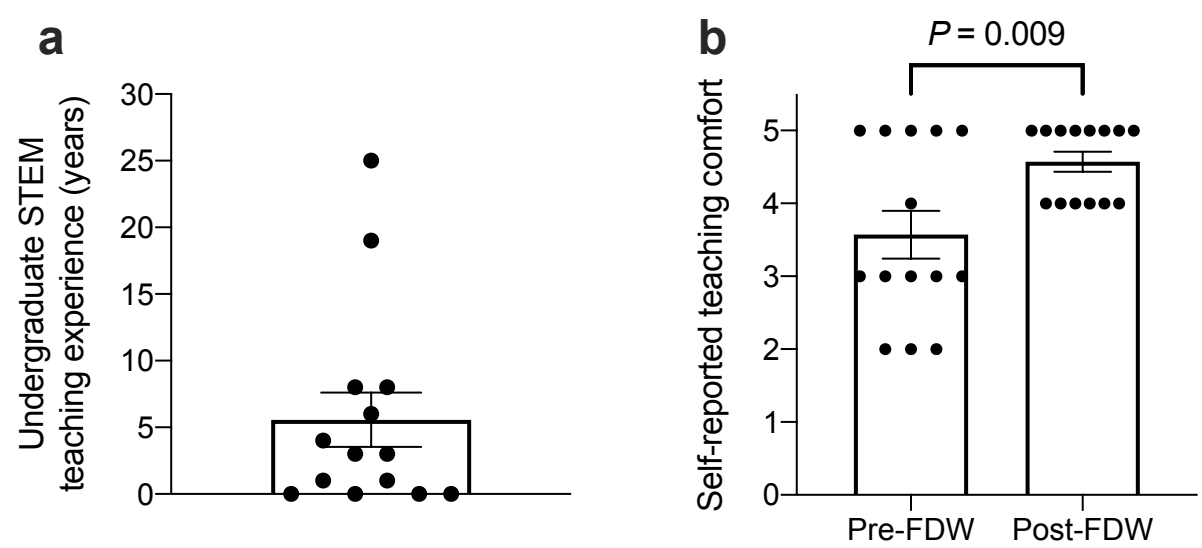

Figure 1. Years of teaching experience and the impact of FDW for surveyed FDW 2020 participants. (a) Instructor experience for the FDW participants, including experienced and new instructors. Bar indicates mean \pm standard error of the mean (s.e.m.) of $\mathrm{N}=14$ faculty. (b) Selfperceived comfort in teaching scores, on a scale of one to five, before and after the faculty member's first FDW experience. Bars indicate mean \pm s.e.m. of $\mathrm{N}=14$ faculty. Data were compared using an unpaired, two-tailed student's t-test. 


\section{Advantages}

\section{Recommendations}

Disadvantages

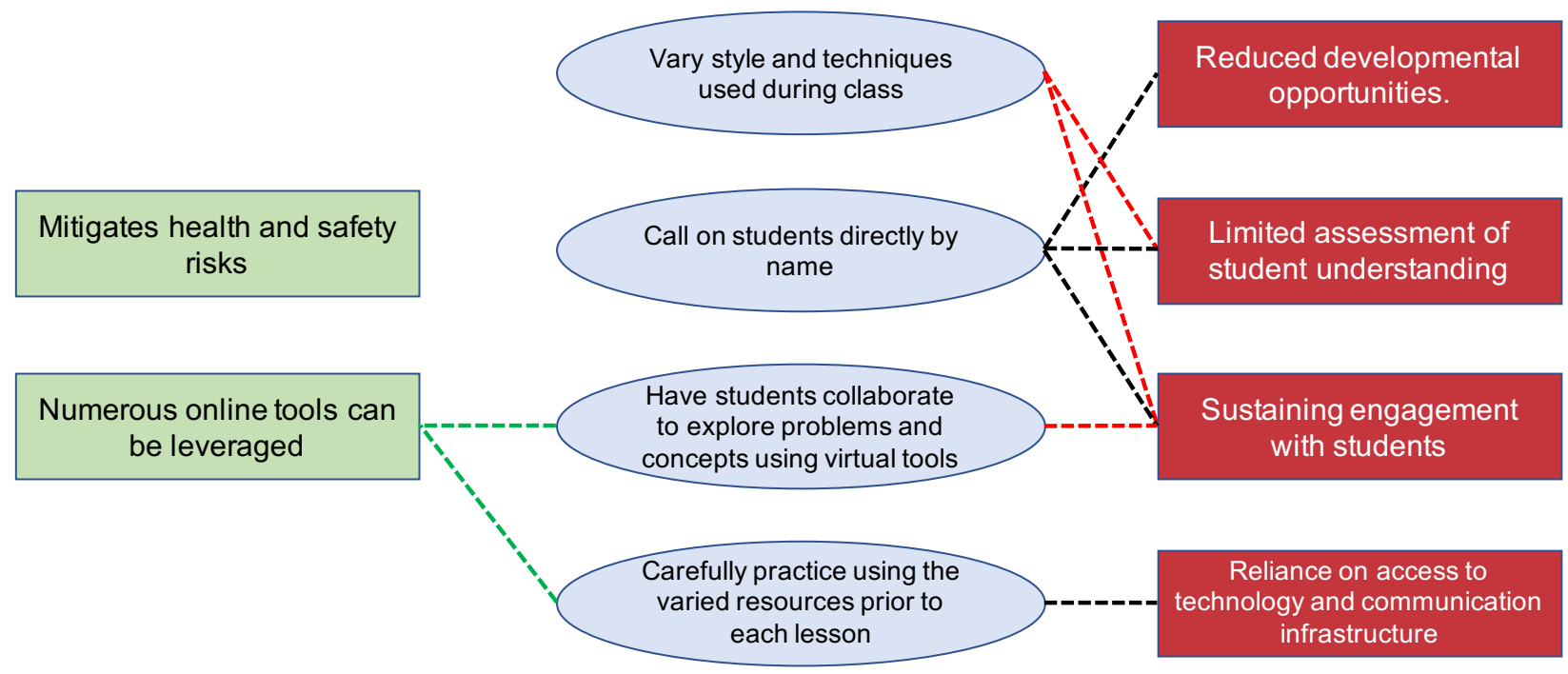

Figure 2. Advantages and disadvantages of remote instruction during COVID-19. Recommendations to strengthen advantages or attenuate disadvantages are shown in the center column. Lines indicate connections between a recommendation and its associated advantages or disadvantages. 


\section{Advantages}

$\underline{\text { Recommendations }}$

Disadvantages

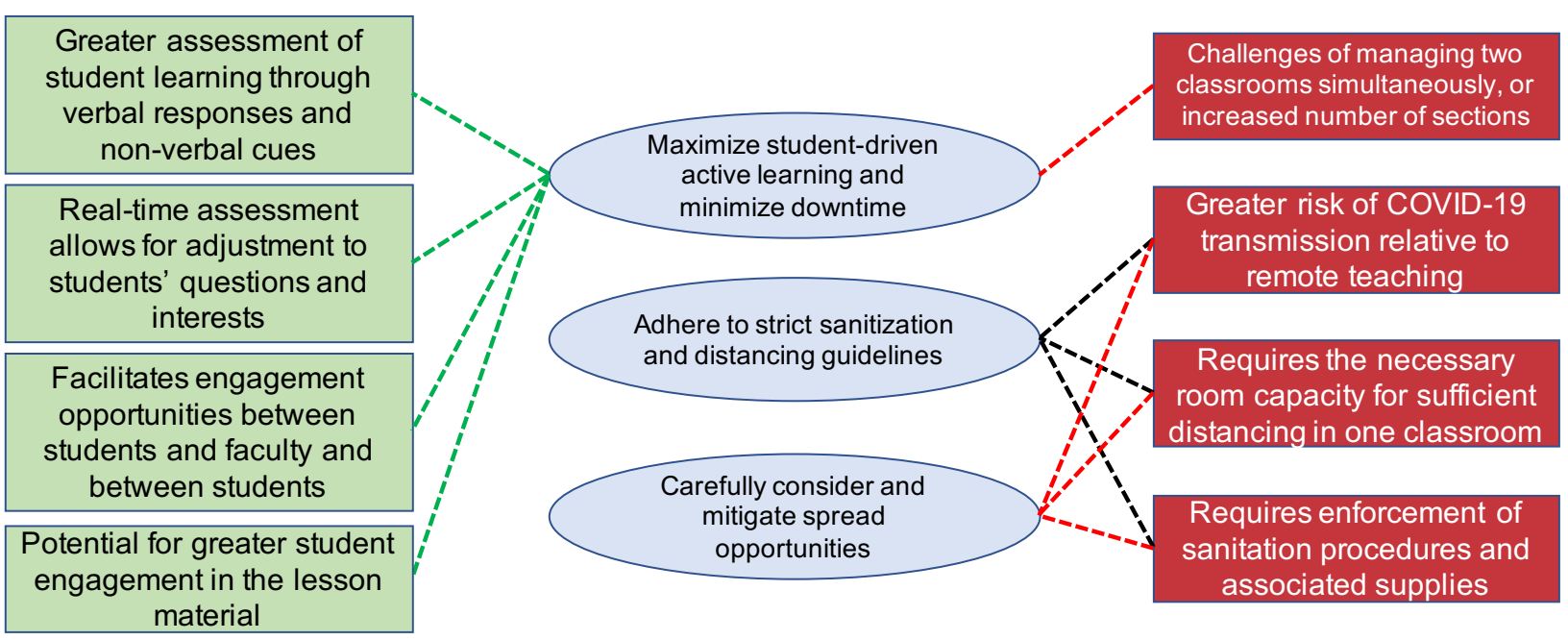

Figure 3. Advantages and disadvantages of in-person instruction during COVID-19.

Recommendations to strengthen advantages or attenuate disadvantages are shown in the center column. Lines indicate connections between a recommendation and its associated advantages or disadvantages. 


\section{Advantages}

Allows for assessment of
student learning through
verbal responses and non-
verbal cues

Real-time assessment allows for adjustment to students' questions and interests

Facilitates rapport building and engagement opportunities between students and faculty, and between students

Allows for adequate distancing in one classroom
Recommendations

Disadvantages

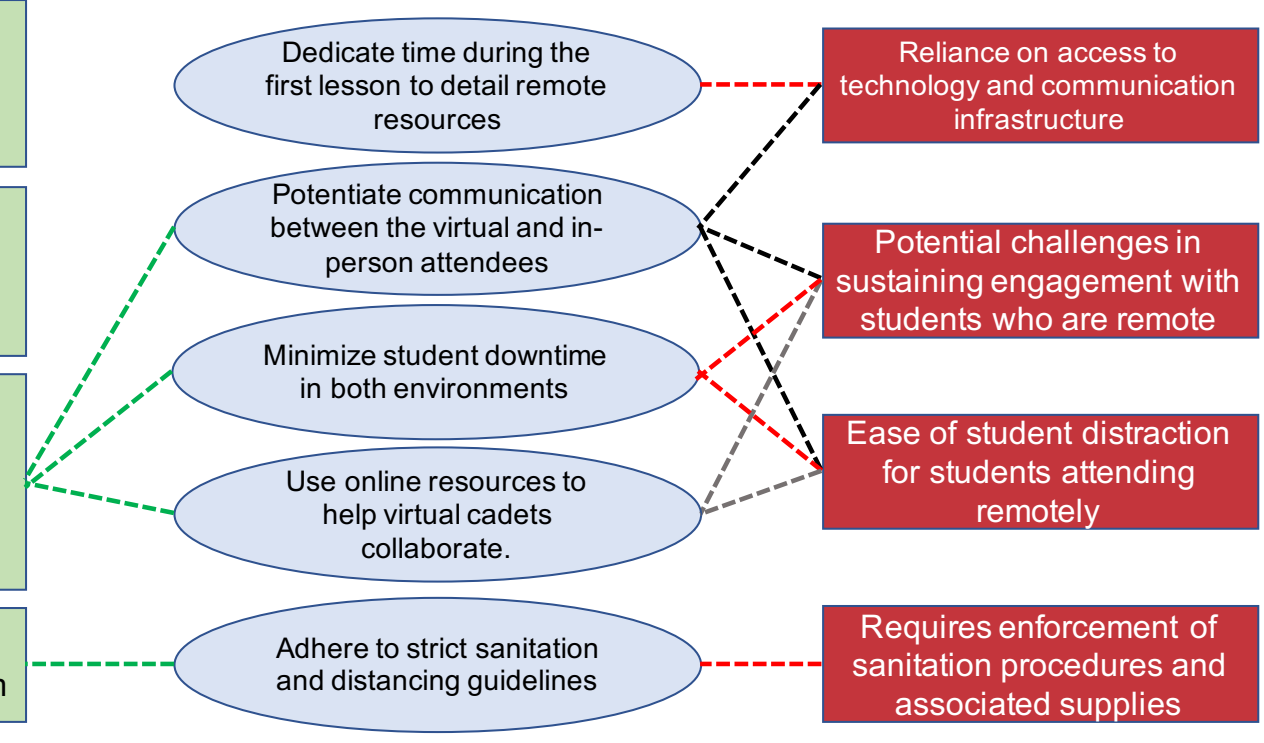

Figure 4. Advantages and disadvantages of hybrid instruction during COVID-19.

Recommendations to strengthen advantages or attenuate disadvantages are shown in the center column. Lines indicate connections between a recommendation and its associated advantages or disadvantages. 


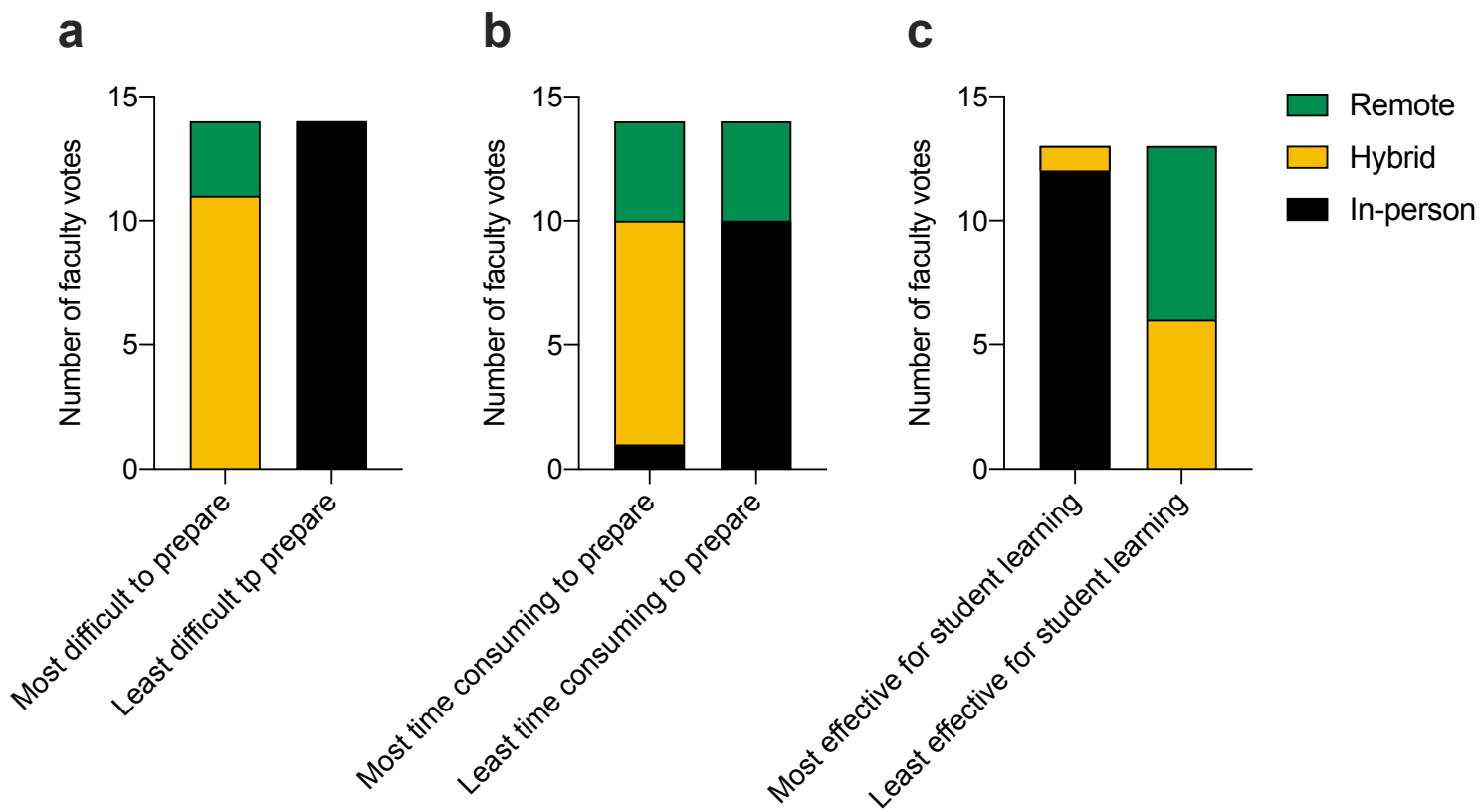

Figure 5. Faculty perceptions of the described modalities for teaching during COVID-19. In considering fully remote (green), hybrid (gold), and entirely in-person (black) formats for teaching during COVID-19, faculty were asked to indicate their opinion on: (a) the most and least difficult method to prepare for ( $\mathrm{N}=14$ responses), (b) the most and least time consuming to prepare for $(\mathrm{N}=14$ responses), and (c) the most and least effective for student learning ( $\mathrm{N}=13$ responses). 


\section{Supplementary information for:}

\section{Lessons from the USMA Faculty Development Workshop in teaching STEM courses during COVID-19}

Eric D. Mowles, Chi K. Nguyen, Lam T. Nguyen, Jared E. Hollows, Melissa Eslinger, Eileen M. Kowalski, F. John Burpo, Ryan Limbocker ${ }^{*}$

Department of Chemistry and Life Science, United States Military Academy, West Point, NY 10996, USA

* Correspondence to R.L. (ryan.limbocker@westpoint.edu) 
Instructor:

Date:

Lesson:

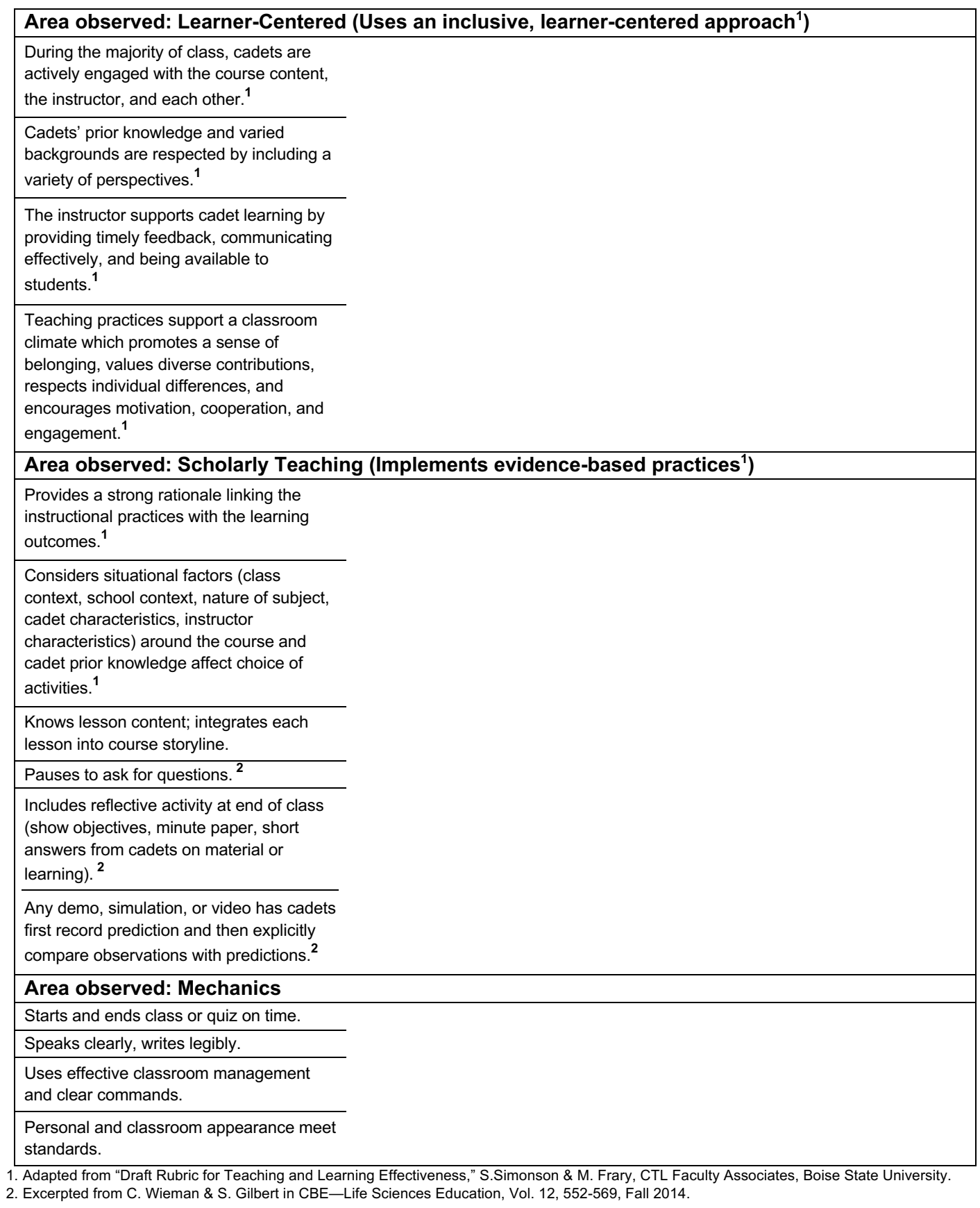

Additional comments on reverse side

Supplementary Figure 1. Template used for instructor feedback. Common form used by senior faculty participants as a guiding template in giving new instructors constructive feedback. 
Learning Objectives:

1. Depict main group atoms with Lewis representations (Lewis symbols).

2. Depict molecules and polyatomic ions with Lewis structures.

3. Analyze Lewis structures using formal charges to select the best possible structure.

4. Relate bond length and bond energy.

5. Recognize which elements energetically favor a diatomic nature.

6. Describe resonance and depict a molecule or polyatomic ion with resonance Lewis structures when a single Lewis structure does not adequately describe it.

7. Depict molecules and polyatomic ions with central atoms that have expanded valence shells, as appropriate.

Key Terms:

\begin{tabular}{|l|l|l|}
\hline resonance & formal charge & triple bond \\
\hline bond energy & double bond & expanded octet \\
\cline { 1 - 2 } lone pair & bond length & \multicolumn{1}{|l}{} \\
\cline { 1 - 2 } &
\end{tabular}

Before Class

Reading: Tro, 2018: Section 4.7, 5.3-5.6 (pgs. 175-177, 210-222)

Mastering Chemistry: “Lesson \#12" Assignment

During/After Class

Tro, 2018: Chapter 4, Exercises 6, 61

Chapter 5, Exercises 6, 10, 11, 13, 14, 28, 30, 32, 36, 38, 40, 50, 51, 52, 80, 86, 97

Supplementary Figure 2. Example lesson assignment sheet. The course director creates the lesson learning objectives, key terms, before class reading (from Tro, N.J., Chemistry: Structure and Properties, $2^{\text {nd }}$ edition) and homework assignment, and after class homework assignment. Instructors are free to teach their classes as they deem best, but need to remain cognizant of the material in the lesson assignment sheet that will be assessed on the common quizzes and tests. 
1. How many years of experience did you have teaching undergraduate STEM courses prior to FDW?

$\#$

2. How comfortable did you feel about teaching at the USMA prior to FDW?

Very Uncomfortable (1), Moderately Uncomfortable, Neutral, Moderately Comfortable, Very Comfortable (5)

3. How comfortable do you feel about teaching at the USMA after completing FDW?

Very Uncomfortable (1), Moderately Uncomfortable, Neutral, Moderately Comfortable, Very Comfortable (5)

4. What method do you believe is the most difficult for an instructor to prepare for?

a. Fully Remote

b. Hybrid with MS Teams

c. Fully in-person

5. What method do you believe is the greatest ease for an instructor to prepare for?

a. Fully Remote

b. Hybrid with MS Teams

c. Fully in-person

6. What method do you believe requires the greatest amount of time for an instructor to prepare for?

a. Fully Remote

b. Hybrid with MS Teams

c. Fully in-person

7. What method do you believe requires the least amount of time for an instructor to prepare for?

a. Fully Remote

b. Hybrid with MS Teams

c. Fully in-person

8. What method do you believe would be the most effective for student learning?

a. Fully Remote

b. Hybrid with MS Teams

c. Fully in-person

9. What method do you believe would be the least effective for student learning?

a. Fully Remote

b. Hybrid with MS Teams

c. Fully in-person

Supplementary Figure 3. Survey questions that were administered to the faculty. Faculty that participated in FDW during the summer of 2020 were asked to answer the above questions for teaching during COVID-19. Participation was fully voluntary and anonymous, and responses were collected using Google Forms. The survey and execution protocol were reviewed by our institution's Human Research Protections Programs and determined to be Exempt. 